INSTITUT NATIONAL DE LA STATISTIQUE ET DES ETUDES ECONOMIQUES

Série des Documents de Travail du CREST

(Centre de Recherche en Economie et Statistique)

\author{
$\mathrm{n}^{\circ}$ 2011-03 \\ No-arbitrage Near-Cointegrated \\ $\operatorname{VAR}(p)$ Term Structure Models, \\ Term Premia and GDP Growth \\ C. JARDET ${ }^{1}$ \\ A. MONFORT ${ }^{2}$ \\ F. PEGORARO 3
}

Les documents de travail ne reflètent pas la position de l'INSEE et n'engagent que leurs auteurs.

Working papers do not reflect the position of INSEE but only the views of the authors.

\footnotetext{
1 Banque de France.

2 CREST, Banque de France and Maastricht University.

3 Banque de France, CREST and HEC Lausanne.
} 


\title{
No-arbitrage Near-Cointegrated VAR $(p)$ Term Structure Models, Term Premia and GDP Growth
}

\author{
Caroline JARDET ${ }^{(1)}$ \\ Banque de France
}

\author{
Alain MONFORT ${ }^{(2)}$ \\ CREST, Banque de France \\ and Maastricht University
}

\author{
Fulvio PEGORARO ${ }^{(3)}$ \\ Banque de France, CREST and HEC Lausanne
}

First version : September, 2008. This version: January, 2011.

\begin{abstract}
No-arbitrage Near-Cointegrated $\operatorname{VAR}(p)$ Term Structure Models, Term Premia and GDP Growth
\end{abstract}

The recent macro-finance yield curve literature has focused on the extraction of a reliable measure of term premia (on long-term bonds) and on their relevant relationship with future economic activity (GDP), because of the practical implications of this relationship for the conduct of the monetary policy. However, the associated empirical findings do not agree neither about term premia empirical properties nor about the importance or even the direction of the above mentioned relationship. The present paper proposes a two-step approach to handle both problems. First, in a VAR setting, we extract a reliable measure of the term premia by means of averaging estimators techniques aiming at optimally solving prediction problems when highly persistence processes are present and, thus, providing a so called Near-Cointegrated $\operatorname{VAR}(p)$ approach. Second, we analyze the dynamic response of the GDP to shocks on the term premia by using the New Information Response Function concept allowing, in particular, to deal with shocks on variables which are filters of the basic ones in the model. Results in both steps are quite different from those appearing in the literature because of a careful treatment of persistence, in the first step, and of the number of lags in the second one. First, we find, coherently with the typical macroeconomic view, and in contrast with OLS-based VAR decompositions, that the NCVAR-based term premium measure is rather stable and contra-cyclical, with the expectation part accounting for most of the yield variability. Second, we find that an increase of the long-term spread caused by a rise of a term premium induces two effects on future economic activity: the impact is negative for short horizons (less than one year), whereas it is positive for longer ones. Therefore, this result suggests that the above mentioned ambiguity could come from the fact that the sign of this relationship is changing over the period that follows the shock.

Keywords: Averaging Estimators, Persistence Problem, Near-Cointegration Analysis, No-Arbitrage Affine Term Structure Model, Term Premia, GDP Growth, New Information Response Functions.

JEL classification: C51, E43, E44, E47, G12.

\footnotetext{
${ }^{1}$ Banque de France, Financial Economics Research Service [DGEI-DEMFI-RECFIN; E-mail: Caroline.JARDET@banque-france.fr].

${ }^{2}$ CREST, Laboratoire de Finance-Assurance [E-mail: monfort@ensae.fr], and Banque de France, Financial Economics Research Service [DGEI-DEMFI-RECFIN].

${ }^{3}$ Banque de France, Financial Economics Research Service [DGEI-DEMFI-RECFIN; E-mail:
} 


\section{Introduction}

The recent macro-finance yield curve literature has focused on the extraction of a reliable measure of term premia (on long-term bonds) and on their relevant relationship with future economic activity, because of the practical implications of this relationship for the conduct of the monetary policy. As far as the extraction of the term premia is concerned, we observe relatively little consensus about their empirical properties. Indeed, while the typical macro wisdom requires a stable and contra-cyclical term premium with long-term yield movements mostly driven by the expectation component, recent papers by Kim and Orphanides (2005, 2007) and Beechey (2007) find, in sharp contrast, that the term premium measure has a large variability, the expectation part being rather stable. Other papers like Rudebusch and Wu (2008) and Bauer (2010) find, contradicting again the typical macroeconomic view, a term premium which is extremely stable and neutral with respect to the business cycle.

Regarding the link between term premia and future economic activity, some studies based on static regressions like those by Hamilton and Kim (2002), and Favero, Kaminska and Sodestrom (2005) find a positive relation between term premium and economic activity. In contrast, Ang, Piazzesi and Wei (2006), Rudebusch, Sack and Swanson (2007), and Rosenberg and Maurer (2007) find that the term premium has no predictive power for future GDP growth. Practitioners and private sector macroeconomic forecasters views suggest a relation of negative sign between term premium and economic activity. This negative relationship is usually explained by the fact that

Fulvio.PEGORARO@banque-france.fr], CREST, Laboratoire de Finance-Assurance [E-mail: pegoraro@ensae.fr] and HEC Lausanne, Department of Finance and Insurance.

We received helpful comments and suggestions from David Backus, Michael Bauer, Mike Chernov, John Cochrane, Valentina Corradi, Pasquale Della Corte, Greg Duffee, Carlo Favero, Christian Gourieroux, Stéphane Grégoir, Lars Peter Hansen, Peter Hoerdhal, Scott Joslin, Sharon Kozicki, Nour Meddahi, Philippe Mueller, Monika Piazzesi, Mark Reesor, Jeff Russell, Mark Salmon, Ken Singleton, Eric T. Swanson, Fabio Trojani, Amir Yaron and seminar participants at the September 2008 Bank of Canada Conference on "Fixed Income Markets", October 2008 CREST Financial Econometrics Seminar, November 2008 Bank of France Conference on "Financial Markets and Real Activity", March 2009 University of Lugano (USI) Finance Seminar, April 2009 Warwick Finance Seminars, June 2009 Bank of France - Bundesbank Conference on "The Macroeconomy and Financial Systems in Normal Times and in Times of Stress", EFA 2009 Conference, ESEM 2009 Conference, Toulouse School of Economics Financial Econometrics Conference 2010. 
a decline of the term premium, maintaining relatively low and stable long rates, may stimulate aggregate demand and economic activity, and this explanation implies a more restrictive monetary policy to keep stable prices and the desired rate of growth. Because of the lack of agreement among the empirical findings, policy makers have no precise indication about the stimulating or shrinking effect of term premia on gross domestic product (GDP) growth [see Rudebusch, Sack and Swanson (2007), and the references there in, for more details].

This paper tries to propose a solution to both the unclear empirical properties of the term premium and its ambiguous relationship with economic activity by, first, extracting a reliable measure of long-term premia by means of a no-arbitrage Gaussian $\operatorname{VAR}(p)$ yield curve model and providing, then, a dynamic (instead of static, like in the above mentioned literature) analysis of the relationship between these two variables.

Coping with the first part of the problem asks for precise short rate forecasts over long horizons (by definition of term premia), and this requirement is particularly challenging once we realize the effects of the strong persistence of interest rates on the specification and estimation of VAR models. Indeed, on the one hand, the presence of "nearly non-stationary" processes in the VAR factor leads to impose cointegration relationships (unit roots) in the parametric specification (CVAR models) and, thus, associated forecasts at any horizon are very similar and close to the present value of the variable of interest. On the other hand, if we take into account the low power of cointegration/unit root tests against highly persistent alternatives, and we use an unconstrained VAR model, the obtained forecasts tend to quickly converge to the unconditional mean of the variable. This sharp difference between CVAR-based and VAR-based long-horizon forecasts [see Cochrane and Piazzesi (2008)] automatically generates uncertainty about the reliability of the associated measures of the term premia. In addition, in finite sample, the magnitude of this difference is exacerbated by the well known "bias problem", that is the downward bias in the OLS estimator (of the unconstrained VAR model) induced, again, by the above mentioned huge serial dependence in yields [see Kim and Orphanides (2007) for a discussion of these problems]. In order to handle this problem, we have 
chosen what we name the Near-Cointegration approach: we estimate the stationary VAR dynamics (the data generating process) of our factor of interest $\left(X_{t}\right)$ (say) by an averaging estimator $\grave{a}$ la $\mathrm{B}$. Hansen (2010) instead of the classical OLS estimator. More precisely, this methodology is based on averaging the estimates of a $\operatorname{CVAR}(p)$ and of the associated unconstrained $\operatorname{VAR}(p)$ model, and the averaging weight is obtained by minimizing the root mean squared forecast error of a variable of interest. Since our aim is to extract reliable measures of term premia, this variable is chosen to be the function of future short rates appearing in the expectation part of the long-term yield. This methodology seems to be particularly adapted to the term premia extractions given the promising forecast performances this kind of estimator has shown in Monte Carlo experiments as indicated by B. Hansen (2010) and confirmed by Jardet, Monfort and Pegoraro (2009a) in a successful comparison with bias-corrected estimators like Indirect Inference estimator, Bootstrap estimator, Kendall's estimator and Median-unbiased estimator ${ }^{4}$. We thus specify and estimate a Near-Cointegrated $\operatorname{VAR}(p)$ yield curve model with stochastic market price of factor risk depending on present and lagged factor values. We find that our approach provides, in terms of root mean square forecast error and among the competing models, the best extraction of the 10-year term premium, that is, the most reliable decomposition of the long-term yield into expectation part and term premium. Coherently with the typical macroeconomic view, the NCVAR-based term premium measure is rather stable and contra-cyclical, with the expectation part accounting for most of the yield variability. On the contrary, the (less reliable) OLS-based VAR decompositions, strongly affected by the persistence problem, assign a large portion of the long-term yield variability to the term premium [as in Beechey (2007)], while the CVAR model leads to systematically identify (regardless the degree of persistence of the sample period) this measure with the long-term spread.

We handle the second part of the problem, namely the dynamic relationship between the term premia and economic activity, by applying a generalization of the notion of Impulse Response

\footnotetext{
${ }^{4}$ It is important to point out that the averaging estimator strategy does not imply any parameter or model uncertainty of the investor [like, for instance, in L.P. Hansen and Sargent $(2007,2008)$ ]. It is a statistical procedure adopted by the econometrician to propose estimation methods improving the out-of-sample forecast performances of the model.
} 
Function, that is, the concept of New Information Response Function introduced by Jardet, Monfort and Pegoraro (2009b). This approach allows us, in particular, to measure the dynamic effects, on any variable, of a new (unexpected) information at a given date, regarding any state variables, any yield to maturity or any linear filter of that variables. We provide, first, a dynamic analysis of the relationship between the long-term spread and future economic activity and then, we disentangle the effects of a rise of the spread entirely due to an increase of its expectation part, and a rise of the spread caused by an increase of the term premium only. Like in most studies proposed by the economic literature, we find that an increase of the spread implies a rise of the economic activity. We find similar results when the rise of the spread is generated by an increase of its expectation part. In contrast, an increase of the spread caused by a rise of the term premium induces two effects on future output growth: the impact is negative for short horizons (less than one year), whereas it is positive for longer ones. Our results suggest that, the ambiguity found in the literature regarding the sign of the relationship between the term premium and future activity, could come from the fact that the sign of this relationship is changing over the period that follows the shock.

The paper is organized as follows. Section 2 gives a motivation for the use of the averaging estimator à la B. Hansen (2010), based on its prediction performances, while Section 3, after the description of the data, presents the Near-Cointegration methodology leading to a persistent but stationary $\operatorname{VAR}(p)$ dynamics for the factor of interest $X_{t}=\left(r_{t}, S_{t}, g_{t}\right)^{\prime}$, where $r_{t}$ is a short rate, $S_{t}$ a long-term spread and $g_{t}$ is a one-period gross domestic product (GDP) growth rate. These variables are also considered in the pioneering paper of Ang, Piazzesi and Wei (2006) [APW (2006), hereafter] whose model constitutes a benchmark of our study. More precisely, this section stresses the persistence problem, presents a solution based on averaging estimators, and then specifies and estimates the Near-Cointegrated $\operatorname{VAR}(p)$ factor dynamics. Section 4 shows how the NearCointegrated model can be completed by a no-arbitrage affine term structure model, presents risk sensitivity parameter estimates, proposes a reliability check of our selected averaging parameter and focuses on the empirical performances of our model in terms of in-sample fit of the whole yield 
curve. Section 5 defines our preferred NCVAR-based measure of term premia, and compares it with those extracted by cointegrated and unconstrained VAR affine models. Section 6, using the general concept of New Information Response Function, studies the dynamic relationships between the spread, its components (expectation part and term premia) and the GDP growth. Section 7 concludes, while Jardet, Monfort and Pegoraro (2010) provides an online appendix with additional details, results and tables ${ }^{5}$ about state dynamics specification, in-sample fit of the yield curve and response functions.

\section{Persistence, prediction and averaging estimators}

\subsection{Reliability of Term Premia Measurements}

The first problem that this paper tries to tackle, in order to precisely study the relation between term premia and future economic activity, is the extraction of a reliable measure of such term premia, in particular long-horizon ones. Since a term premium is the difference between a yield and the prediction of a function of future short rates, the reliability of its measurement is the same issue as the reliability of the prediction of the above mentioned function of future short rates.

It is well known that the short rate variable, as well as any yield, is very persistent and that standard unit root tests usually accept that it is non-stationary. However, it is difficult to admit nonstationarity because it would imply unrealistic asymptotic behaviors and it is generally considered that the short rate dynamics is stationary but close to non-stationarity or "near non-stationary". At this stage another problem occurs, namely the well know fact that the OLS or ML estimation methods highly underestimate the persistence because large biases appear in the finite sample behavior of these estimators [see e. g. Kendall (1954)]. So, important questions we will have to answer are the followings: Are prediction performances deteriorated by these biases ? Are bias correction methods appropriate for improving prediction performances ? Is there a better way to

\footnotetext{
${ }^{5}$ These tables will be labeled by the lower case arabic $a$. letter and lower case roman numerals.
} 


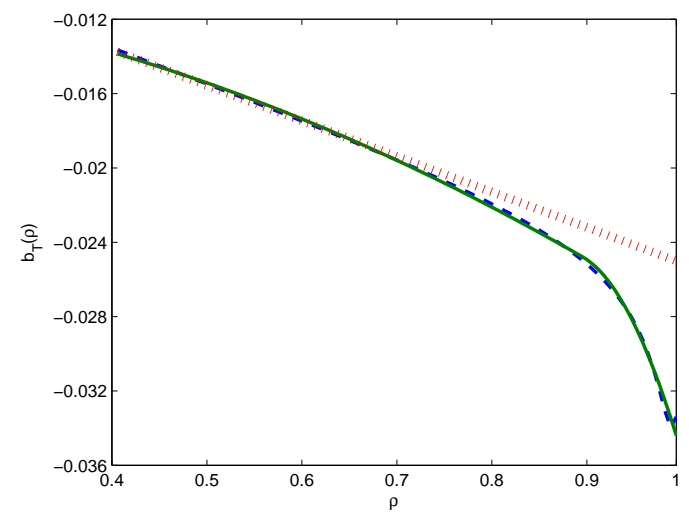

Figure 1:

Bias of the OLS estimator $\hat{\rho}_{T}$ (sample size $T=160$ ): exact (green solid line), spline approximation (blue dashes) and Kendall's approximation (red dots).

improve forecast performances? We will provide answers to these questions in the next section.

\subsection{Bias correction vs Averaging Estimators}

In order to motivate the approach retained in this paper for the prediction of (a function of) persistent variables, let us consider a simple $\operatorname{AR}(1)$ model $y_{t}=\mu(1-\rho)+\rho y_{t-1}+\varepsilon_{t}, t \in\{1, \ldots, T\}$, where the $\varepsilon_{t}$ 's are independently distributed as $N\left(0, \sigma^{2}\right), y_{0}=\mu$ and $T=160$, which is a typical sample size in empirical studies based on quarterly data. It is easy to study the behavior of the OLS estimator $\hat{\rho}_{T}$ of $\rho$, by Monte Carlo methods and for various values of $\rho$ (note that this behavior does not depend on $\mu$ and $\sigma^{2}$. In particular, using 50.000 simulations we can compute the bias of $\hat{\rho}_{T}$, namely $b_{T}(\rho)=E_{\rho}\left(\hat{\rho}_{T}\right)-\rho$. Figure 1 shows the bias function $b_{T}(\rho)$ for $\left.\rho \in\right] 0.4,1[$, as well as the Kendall approximation $-(1+3 \rho) / T$ (and a quadratic spline approximation $b_{T}^{S}(\rho)$ of $b_{T}(\rho)$ which will be useful below). It is clear from this figure that the bias is very large and, moreover, for $\rho$ close to one this bias is much worse than its Kendall's approximation.

Since the main focus of this paper is the prediction of a function of future short rates, in order to extract measures of term premia, a natural question is to evaluate the property of biascorrected estimators in terms of prediction. There are many methods to approximately correct 
for bias and here we retain the one which has been recognized as very efficient [see Gourieroux, Monfort and Renault (1993), Gourieroux and Monfort (1996), Gourieroux, Touzi and Renault (2000) and Duffee and Stanton (2008)]: the indirect inference estimator defined by $\hat{\rho}_{T}^{I}=e_{T}^{-1}\left(\hat{\rho}_{T}\right)$, where $e_{T}(\rho)=E_{\rho}\left(\hat{\rho}_{T}\right)$ is approximated by $\rho+b_{T}^{S}(\rho)$. We also consider another kind of estimators, namely the class of "averaging estimators" proposed by B. Hansen (2010) and defined as a weighted average of the estimator of $\rho$ in the non-stationary model, i.e. 1 in our case, and in the stationary one, i.e the OLS estimator $\hat{\rho}_{T}$ :

$$
\hat{\rho}_{T}^{A}(\lambda)=(1-\lambda)+\lambda \hat{\rho}_{T}, \quad 0 \leq \lambda \leq 1
$$

We compare, in a Monte Carlo exercise, with 50.000 simulations and $\rho=0.99$, the predictions of $y_{t}$, obtained from the above mentioned $\mathrm{AR}(1)$ process, when the autoregressive parameter is estimated by $\hat{\rho}_{T}^{I}$ and by $\hat{\rho}_{T}^{A}(\lambda)$. For each simulation, we compute a path of 180 observations, we calculate the OLS estimator of $\rho$ (from the first $T=160$ observations), we determine $\hat{\rho}_{T}^{I}$ and $\hat{\rho}_{T}^{A}(\lambda)$, and then we generate the associated forecasts at horizon $q=1$ and $q=20$. The comparison among the forecast performances is based on the root mean squared forecast error (RMSFE), normalized by the one based on the true value of $\rho$. The results are given in Figure $2(q=1)$ and Figure 3 $(q=20)$.

The performances of the optimal averaging estimator, obtained with $\lambda \approx 0.25$ both for $q=1$ and $q=20$, is by far the best one; in the case $q=20$, for instance, the percentage of increase of the RMSFE, compared with the one obtained from the true parameter value, is about three times smaller than for the indirect inference estimator and five times smaller than for the OLS estimator. Similar conclusions are obtained for different values of $T$ and $\rho$ and for bivariate models close to cointegration or "near-cointegrated" [see Jardet, Monfort and Pegoraro (2009a)]. These results clearly provide solid arguments in favor of the averaging estimator class, compared to the optimal bias correction method based on indirect inference, in terms of forecast performances and, thus, in terms of term premia extraction. 


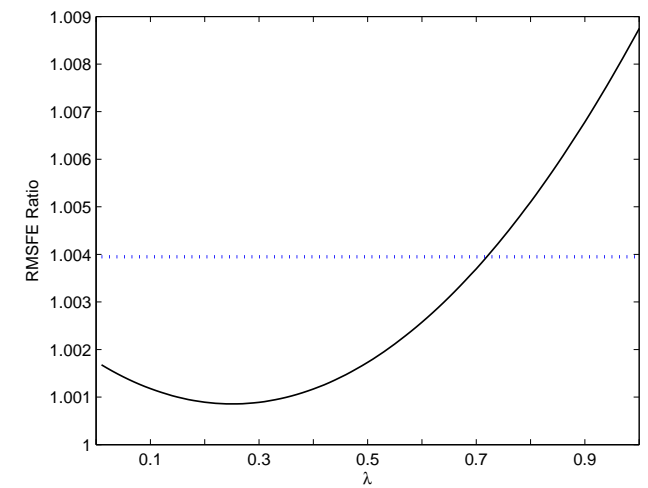

Figure 2:

RMSFE ratio with $\rho=0.99, T=160, q=1$. $\hat{\rho}_{T}^{A}(\lambda)$ (blue solid curve), $\hat{\rho}_{T}^{I}$ (green dots).

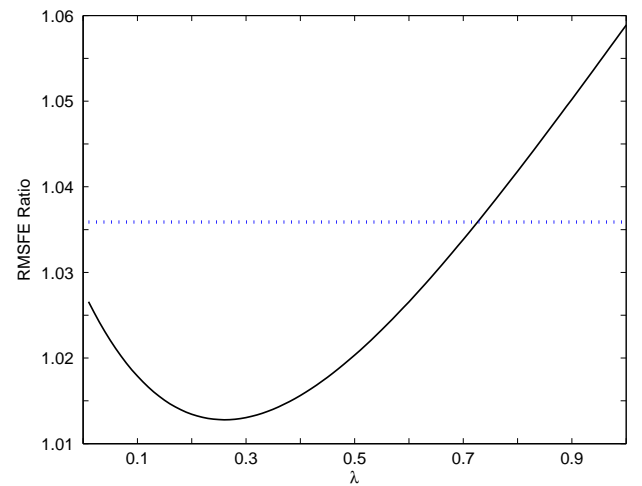

Figure 3:

RMSFE ratio with $\rho=0.99, T=160, q=20$. $\hat{\rho}_{T}^{A}(\lambda)$ (blue solid curve), $\hat{\rho}_{T}^{I}$ (green dots).

\section{Near-Cointegration Analysis}

\subsection{Description of the Data}

The data set that we consider in the empirical analysis contains 174 quarterly observations of U. S. zero-coupon bond yields, for maturities 1, 2, 3, 4, 8, 12, 16, 20, 24, 28, 32, 36 and 40 quarters, and U. S. real GDP, covering the period from 1964:Q1 to 2007:Q2. The yield data are obtained from Gurkaynak, Sack, and Wright (2007) [GSW (2007), hereafter] data base and from their estimated Svensson (1994) yield curve formula. In particular, given that GSW (2007) provide interest rate values at daily frequency, each observation in our sample is given by the daily value observed at the end of each quarter. The same data base is used by Rudebusch, Sack, and Swanson (2007) [RSS (2007), hereafter] in their study on the implications of changes in bond term premiums on economic activity. Observations about real GDP are seasonally adjusted, in billions of chained 2000 dollars, and taken from the FRED database $(\mathrm{GDPC} 1)^{6}$. The short rate $\left(r_{t}\right)$ and the long rate $\left(R_{t}\right)$ are respectively given by the 1 -quarter and 40-quarters yields.

\footnotetext{
${ }^{6}$ See Jardet, Monfort and Pegoraro (2010) for further details.
} 


\subsection{Near-Cointegrated VAR $(p)$ Dynamics}

\subsubsection{Handling the Persistence Problem for Term Premia Extraction}

We first apply unit root tests and a cointegration analysis to the joint autoregressive dynamics of the short rate $\left(r_{t}\right)$, the long rate $\left(R_{t}\right)$ and the log-GDP $\left(G_{t}\right)$, collected in a vector denoted by $Y_{t}$. This econometric procedure leads us to a vector error correction model, with two lags, for $\Delta Y_{t}$, that we can write as a Cointegrated $\operatorname{VAR}(3)$, or $\operatorname{CVAR}(3)$, for $X_{t}=\left(r_{t}, S_{t}, g_{t}\right)^{\prime}$, the long-term spread $S_{t}=R_{t}-r_{t}$ being the only cointegrating relationship ${ }^{7}$. We thus obtained a constrained estimator, denoted by $\widehat{\theta}_{T, \text { cvar }}$ [see table a.viii)], of the true value of the parameter $\theta^{(o)}:=\left(\nu^{(o)}, \Phi_{1}^{(o)}, \Phi_{2}^{(o)}, \Phi_{3}^{(o)}\right)$ appearing in the data generating process (DGP):

$$
X_{t}=\nu^{(o)}+\sum_{j=1}^{3} \Phi_{j}^{(o)} X_{t-j}+\eta_{t}^{(o)}, \eta_{t}^{(o)} \sim \operatorname{IIN}\left(0, \Omega^{(o)}\right)
$$

Another estimator of $\theta^{(o)}$ is obtained by the unconstrained OLS method applied to the stationary $\operatorname{VAR}(3)$ model, and it is denoted by $\widehat{\theta}_{T, v a r}$ [see table $\left.\left.a . i x\right)\right]$.

The CVAR(3) specification suggested by the cointegration analysis has, on the one hand, the advantage to explain the autocorrelation in interest rates better than the unconstrained counterpart given by a VAR(3) model for $X_{t}$, but, on the other hand, has two important drawbacks. First, it assumes the non-stationarity of interest rates, while a wide literature on nonlinear models indicates that they are highly persistent but stationary [see, for instance, Gray (1996) and Ang and Bekaert (2002), and the references therein]. Second, interest rate forecasts over long horizons, coming from the alternative CVAR(3) and $\operatorname{VAR}(3)$ estimated dynamics, have unrealistic behaviors. For any given date in the sample period, we show these forecasts in figures 4 and 5, for the CVAR(3) and VAR(3) specifications, respectively, for a forecasting horizon $q$ (say) rising from 1 to 40 quarters. In the CVAR(3) case (figure 4) the predictions remain close to the present value when $q$ increases and

\footnotetext{
${ }^{7}$ Details about VAR order selection, unit root tests and cointegration analysis are presented in Jardet, Monfort and Pegoraro(2010).
} 
in the $\operatorname{VAR}(3)$ case (figure 5) they revert to the unconditional mean. As a consequence, important differences will be found in the term premia extraction [see also Cochrane and Piazzesi (2008)].

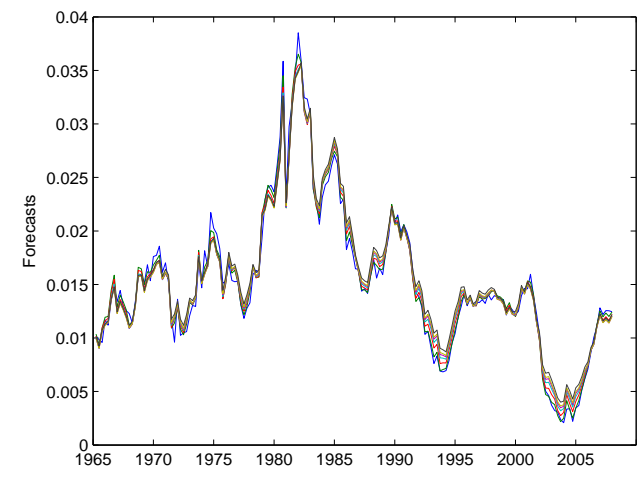

Figure 4:

$q$-step ahead short rate forecasts from the CVAR(3) model; $q=1,4,8,12,16,20,40$ quarters.

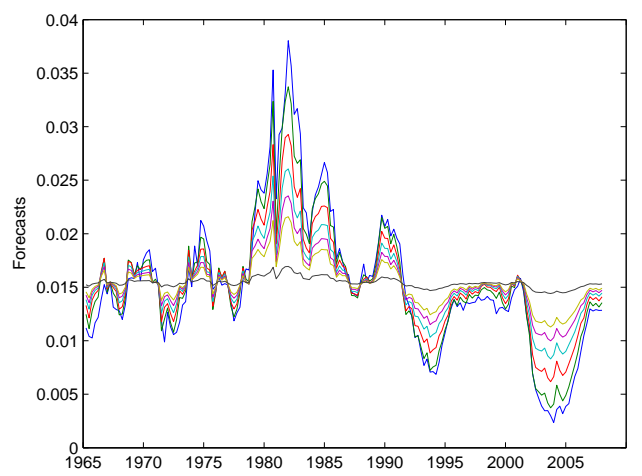

Figure 5:

$q$-step ahead short rate forecasts from the $\operatorname{VAR}(3)$ model; $q=1,4,8,12,16,20,40$ quarters.

As mentioned above, in this paper we adopt the class of averaging estimators, considered in Section 2 and proposed by B. Hansen (2010), in order to tackle the estimation problems induced by the interest rate persistence and affecting forecast performances. Hansen's results have been derived in a univariate and one-step-ahead framework and their generalization to a multivariate and multihorizon setting raises difficult technical problems, in particular the multiplicity of the parameter paths leading to the constrained VAR at rates proportional to $1 / T$. So we have decided to adopt a pragmatic approach and, extrapolating the Monte Carlo results of Section 2 and of Jardet, Monfort and Pegoraro (2009a), we have checked empirically whether the out-of-sample root mean squared forecast errors, when forecasting some variable of interest at various horizons, are improved when using an averaging estimator based on the $\operatorname{VAR}(3)$ and $\operatorname{CVAR}(3)$ models. As explained below, our empirical findings thoroughly confirm Hansen's theoretical results. 


\subsubsection{Averaging Estimations and Extraction of Short Rate Expectations}

The averaging estimators $\theta_{T}^{(n c)}(\lambda)$ (say) of $\theta^{(o)}$, of the Near-Cointegrated (stationary) VAR(3) dynamics of the state vector $X_{t}$, are obtained in the following way:

$$
\theta_{T}^{(n c)}(\lambda)=\lambda \widehat{\theta}_{T, v a r}+(1-\lambda) \widehat{\theta}_{T, c v a r}
$$

where $\lambda \in[0,1]$ is a free parameter selected to minimize a criterion of interest (for each model, the conditional variance-covariance matrix is estimated from its residuals). Since our aim is to provide a reliable measure of the term premia on long-term bonds, we focus on minimizing the prediction error of the associated expectation part.

Given a yield with residual maturity $h$ at date $t$, denoted by $R_{t}(h)$, we define its expectation term as $E X_{t}(h)=-\frac{1}{h} \log \widetilde{B}_{t}(h)$ with $\widetilde{B}_{t}(h)=E_{t}\left[\exp \left(-\left(r_{t}+r_{t+1}+\ldots+r_{t+h-1}\right)\right)\right]$. The associated term premium is given by $T P_{t}(h)=R_{t}(h)-E X_{t}(h)$ (see Section 5.1 for a more detailed presentation). For a given maturity $h$, the parameter $\lambda=\lambda(h)$ (say) is selected as the solution of the following problem:

$$
\lambda^{*}(h)=\arg \min _{\lambda \in[0,1]} \sum_{t}\left[\widetilde{B}_{t}^{\text {obs }}(h)-\widetilde{B}_{t}(h, \lambda)\right]^{2}
$$

where, for each date $t$ and residual maturity $h, \widetilde{B}_{t}^{\text {obs }}(h)$ is the observed realization of $\exp \left(-r_{t}-\right.$ $\left.\ldots-r_{t+h-1}\right)$ while $\widetilde{B}_{t}(h, \lambda)$ is the $\operatorname{NCVAR}(3)$ model's forecast of $\exp \left(-r_{t}-\ldots-r_{t+h-1}\right)$ using the parameter $\theta_{T}^{(n c)}(\lambda)$ given by (3). The out-of-sample forecasts are performed during the period 1990:Q1 - 2007:Q2, using an expanding window for the estimation of models VAR(3) and CVAR(3). More precisely, we first compute the estimates $\widehat{\theta}_{v a r}$ and $\widehat{\theta}_{\text {cvar }}$ over the period 1964:Q1 to 1989:Q4 and we calculate $\widetilde{B}_{t}(h, \lambda)$ with $t=1989: \mathrm{Q} 4$. Then, at each later point in time $t$, we recompute $\widehat{\theta}_{\text {var }}$ and $\widehat{\theta}_{\text {cvar }}$ taking into account the new observation and, in doing so, we replicate the typical behavior of an investor that incorporates new information over time [see also Favero, Kaminska and Sodestrom (2006)].

In table 1 we compare, for $h$ ranging from 4 to 40 quarters, the RMFSE obtained from the 


\begin{tabular}{rr|c|cc|ccc}
\hline & $h$ & $\begin{array}{c}\mathrm{AR}(1) \\
\text { (Vasicek) }\end{array}$ & $\lambda^{*}(h)$ & NCVAR(3) & CVAR(3) & VAR(3) & VAR(1) \\
\hline & 4 & 0.0071 & 1.0000 & 0.0064 & 0.0066 & 0.0064 & 0.0075 \\
& 8 & 0.0257 & 0.7913 & 0.0228 & 0.0237 & 0.0229 & 0.0261 \\
$\widetilde{B}_{t}^{\text {obs }}(h)$ & 12 & 0.0476 & 0.5667 & 0.0423 & 0.0436 & 0.0429 & 0.0469 \\
& 20 & 0.0882 & 0.1760 & 0.0736 & 0.0742 & 0.0806 & 0.0848 \\
& 32 & 0.1229 & 0.2311 & 0.0991 & 0.1037 & 0.1135 & 0.1196 \\
& 40 & 0.1411 & 0.2617 & 0.1012 & 0.1155 & 0.1224 & 0.1406 \\
\hline
\end{tabular}

Table 1: Out-of-sample forecasts of $\widetilde{B}_{t}^{\text {obs }}(h)=\exp \left(-r_{t}-\ldots-r_{t+h-1}\right)$. Table entries are associated RMSFEs. AR(1) (Vasicek) denotes forecasts of $\widetilde{B}_{t}^{\text {obs }}(h)$ using a Gaussian $\mathrm{AR}(1)$ process describing the dynamics of the (one-quarter) short rate. The residual maturities $(h)$ are measured in quarters.

NCVAR(3) model, with $\lambda^{*}(h)$ being solution of (4), with those obtained by the CVAR(3), VAR(3), $\operatorname{VAR}(1)$ and a short rate $\operatorname{AR}(1)$ models. We observe that, for $h>4$, the $\operatorname{NCVAR}(3)$ estimation outperforms that of the $\operatorname{VAR}(3)$ and $\operatorname{CVAR}(3)$ models: there exists a $\lambda^{*}(h)$, strictly between 0 and 1 , such that the average of the estimated parameters in the CVAR(3) and VAR(3) models improves the forecasts of $\widetilde{B}_{t}^{\text {obs }}(h)$. Even more, the $\operatorname{NCVAR}(3)$ estimation outperforms the (most competing) VAR(1) and $\operatorname{AR}(1)$ models for any $h$; in particular, for long maturities, that is for short rate forecasts over long horizons, it reduces their out-of-sample RMSFEs of 20-30\%.

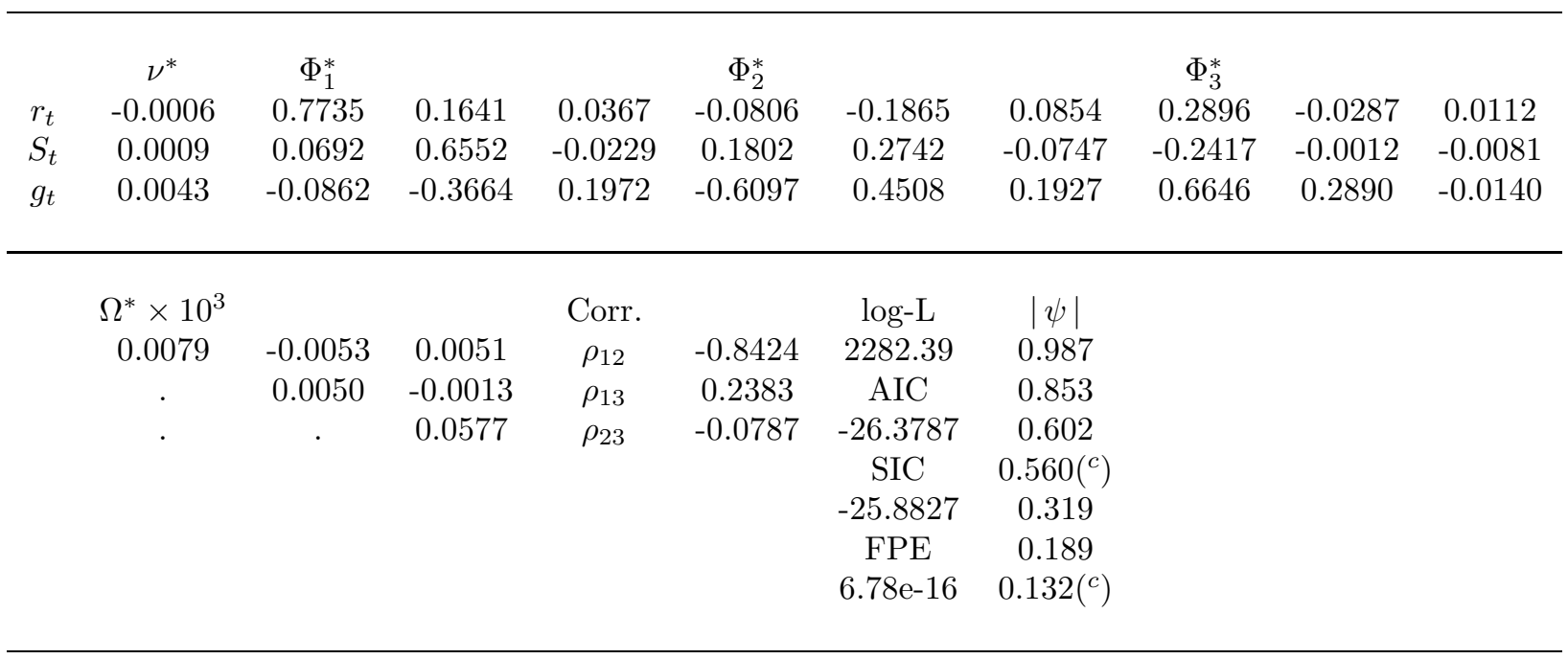

Table 2: Parameter estimates of the true dynamics $X_{t}=\nu^{(o)}+\sum_{j=1}^{3} \Phi_{j}^{(o)} X_{t-j}+\eta_{t}^{(o)}, X_{t}=\left(r_{t}, S_{t}, g_{t}\right)^{\prime}, \eta_{t}^{(o)} \sim$ $\operatorname{IIN}\left(0, \Omega^{(o)}\right)$, with estimator $\theta_{T}^{(n c)}(\lambda)$ and $\lambda=\lambda^{*}(40)=0.26 ; \rho_{i j}$ denotes the empirical correlation between $\left(\eta_{i t}^{(o)}\right)$ and $\left(\eta_{j t}^{(o)}\right) ;|\psi|$ indicates the modulus of the roots of equation $\left|\Phi^{*}(\psi)\right|=0$, with $\Phi^{*}(\psi)=\left(I_{3 \times 3} \psi^{3}-\Phi_{1}^{*} \psi^{2}-\Phi_{2}^{*} \psi-\Phi_{3}^{*}\right)$ denoting the characteristic polynomial; $\left({ }^{c}\right)$ indicates a pair of complex conjugate roots. 
Since, in this work, one of the main objectives is to extract the term premium from the 40quarters long-term bond, we will assume that the $\operatorname{NCVAR}(3)$ state dynamics, driving term structure shapes over time and maturities, is specified by a $\lambda^{*}=\lambda^{*}(40)=0.26$ (see table 2 for the associated parameter estimates). This means that the optimal extraction of the expectation part of the longterm bond is obtained by a stationary $\operatorname{VAR}(3)$ model with estimator $\theta_{T}^{(n c)}\left(\lambda^{*}\right)$ and in which the weight of the CVAR(3) model is three times larger than the one of the unconstrained $\operatorname{VAR}(3)$ model $^{8}$. Thus, the estimated $\operatorname{VAR}(3)$ dynamics now has an autoregressive lag operator with the largest root equal to 0.987 , instead of 0.93 when the OLS estimator is used. We will see in Section 4.3 that, when we select $\lambda$ by minimizing the fitting error of the whole yield curve, we find $\lambda \approx 0.26$ again, thus reinforcing the reliability of our criterion.

\section{Near-Cointegrated Affine Term Structure Models}

\subsection{The Yield Curve Formula}

In the previous sections we have specified and estimated the historical dynamics of the state variable $X_{t}$ as a Near-Cointegrated Gaussian VAR(3) process with averaging parameter given by $\lambda^{*}(40)=$ 0.26. The following step in our modelling procedure aims at deriving the associated arbitrage-free yield-to-maturity formula by specifying a positive stochastic discount factor (SDF) $M_{t, t+1}$ for each period $(t, t+1)$. More precisely, using the notation $\tilde{X}_{t}=\left(X_{t}^{\prime}, X_{t-1}^{\prime}, X_{t-2}^{\prime}\right)^{\prime}$, we assume:

$$
M_{t, t+1}=\exp \left[-r_{t}+\Gamma_{t}^{\prime} \zeta_{t+1}-\frac{1}{2} \Gamma_{t}^{\prime} \Gamma_{t}\right]
$$

where the error term $\eta_{t}^{(o)}$ in $(2)$ is written as $\eta_{t}^{(o)}=\Sigma^{(o)} \zeta_{t}$, with $\zeta_{t} \sim N\left(0, I_{3 \times 3}\right)$, and $\Sigma^{(o)}$ is a lower triangular matrix such that $\Sigma^{(o)} \Sigma^{(o) \prime}=\Omega^{(o)} ; \Gamma_{t}=\gamma_{0}+\gamma \widetilde{X}_{t}=\gamma_{0}+\gamma_{1} X_{t}+\gamma_{2} X_{t-1}+\gamma_{3} X_{t-2}$ is the affine (multiple lags) stochastic risk sensitivity vector; the constant term $\gamma_{0}$ is a $(3 \times 1)$ vector and

\footnotetext{
${ }^{8}$ We have checked that $\lambda$ remains robust to a change in the starting date of the out-of-sample exercise and to a rolling window exercise [see Table a.xii) in Jardet, Montfort and Pegoraro (2010)].
} 
$\gamma=\left[\gamma_{1}: \gamma_{2}: \gamma_{3}\right]$ is a $(3 \times 9)$ matrix. $\gamma_{0}, \gamma_{1}, \gamma_{2}, \gamma_{3}$ are called risk sensitivity parameters.

Given that under the absence of arbitrage opportunity assumption (A.A.O.) the price $B_{t}(h)$ at date $t$ of a zero-coupon bond (ZCB) maturing at $t+h$ is equal to $E_{t}\left[M_{t, t+1} \ldots M_{t+h-1, t+h}\right]$, we have the following result.

Proposition: Let us assume that the factor $X_{t}$ follows, under the historical probability, the Gaussian VAR(3) dynamics (2). Then, the yield with $h$ periods to maturity at date $t$, denoted $R_{t}(h)$, is given by:

$$
\begin{aligned}
R_{t}(h)=-\frac{1}{h} \log B_{t}(h) & =-\frac{c_{h}^{\prime}}{h} \widetilde{X}_{t}-\frac{d_{h}}{h} \\
& =-\frac{c_{1, h}^{\prime}}{h} X_{t}-\frac{c_{2, h}^{\prime}}{h} X_{t-1}-\frac{c_{3, h}^{\prime}}{h} X_{t-2}-\frac{d_{h}}{h}, \quad h \geq 1,
\end{aligned}
$$

where $c_{h}$ and $d_{h}$ satisfies, for $h \geq 1$, the recursive equations:

$$
\left\{\begin{array}{l}
c_{h}=-\widetilde{e}_{1}+\Phi^{(o) \prime} c_{h-1}+\left(\Sigma^{(o)} \gamma\right)^{\prime} c_{1, h-1}, \\
d_{h}=c_{1, h-1}^{\prime}\left(\nu^{(o)}+\Sigma^{(o)} \gamma_{0}\right)+\frac{1}{2} c_{1, h-1}^{\prime} \Sigma^{(o)} \Sigma^{(o) \prime} c_{1, h-1}+d_{h-1}
\end{array}\right.
$$

where :

$$
\Phi^{(o)}=\left[\begin{array}{ccc}
\Phi_{1}^{(o)} & \Phi_{2}^{(o)} & \Phi_{3}^{(o)} \\
I_{3 \times 3} & 0_{3 \times 3} & 0_{3 \times 3} \\
0_{3 \times 3} & I_{3 \times 3} & 0_{3 \times 3}
\end{array}\right] \text { is a }(9 \times 9) \text { matrix }
$$

with initial conditions $c_{0}=0, d_{0}=0\left(\right.$ or $\left.c_{1}=-\widetilde{e}_{1}, d_{1}=0\right)$, where $\widetilde{e}_{1}$ is the $(9 \times 1)$ vector with all entries equal to 0 except the first one equal to 1 , and where $c_{1, h}$ is the vector of the first 3 components of the 9-dimensional vector $c_{h}$ (Proof: straightforward).

So, $R_{t}(h)$ is an affine function of the factor $\widetilde{X}_{t}$, that is of the three most recent lagged values of the 
3-dimensional factor $X_{t+1}$. Note that the risk-neutral dynamics of $X_{t}$ is given by:

$$
X_{t}=\left(\nu^{(o)}+\Sigma^{(o)} \gamma_{0}\right)+\sum_{j=1}^{3}\left(\Phi_{j}^{(o)}+\Sigma^{(o)} \gamma_{j}\right) X_{t-j}+\xi_{t}^{(o)}, \quad \xi_{t}^{(o)} \stackrel{\mathbb{Q}}{\sim} \operatorname{IIN}\left(0, \Omega^{(o)}\right)
$$

Joslin, Priebsch and Singleton (2010) [JPS (2010), hereafter] also have recently specified their yield curve model as a particular Near-Cointegrated VAR(1) model. They handle the bias problem by imposing the largest eigenvalue of the historical autoregressive matrix to be equal to the (close to one) largest eigenvalue of the risk-neutral one. It is also important to stress that the presence of $p$ lagged factor values in (6) does not allow to conclude that the macro factor $X_{t}$ is spanned by the yield curve at the same date. Indeed, at date $t$ we could build from (6) a system with nine observed yields $\mathcal{R}_{t}$ (say) and nine unknowns (the components of $\widetilde{X}_{t}$ ) that we could solve to obtain $X_{t}$, for instance, but the same procedure applied at dates $t+1$ and $t+2$ would give different values for $X_{t}$ since the observed yields do not exactly satisfy equation (6). In order to correctly invert the yield curve formula, we have to introduce in (6) the lag operator $L$ and once we write (with obvious notation) the system $\mathcal{R}_{t}=\left(\mathcal{C}_{1}+\mathcal{C}_{2} L+\mathcal{C}_{3} L^{2}\right) X_{t}+\mathcal{D}=\mathcal{C}(L) X_{t}+\mathcal{D}$, we find by inversion of $\mathcal{C}(L)$ that the $X_{t}$ is function of present and past values of the yield curve, and not just the current one like in the case where there is only one lag in the VAR.

\subsection{Risk Sensitivity Parameter Estimates}

The estimation of historical and risk sensitivity parameters follows a consistent two-step procedure, as adopted, among the others, by APW(2006), Monfort and Pegoraro (2007), and Garcia and Luger (2007). The estimation of risk sensitivity parameters $\theta_{\gamma}=\left(\gamma_{0}, \gamma_{1}, \gamma_{2}, \gamma_{3}\right)$ is obtained by constrained nonlinear least squares (CNLLS), using the observations on yields with maturities different from those used in the first step (that is, maturities ranging from 2-quarters to 36-quarters) and taking the historical parameters at their $\operatorname{NCVAR}(3)$ estimated values. A constraint is imposed in order to satisfy the no arbitrage restriction on the 10-years yield (the long rate). This Constrained NLLS 
estimator is given by:

$$
\left\{\begin{array}{l}
\hat{\theta}_{\gamma}=\operatorname{Arg} \min _{\theta_{\gamma}} S^{2}\left(\theta_{\gamma}\right) \\
S^{2}\left(\theta_{\gamma}\right)=\sum_{t} \sum_{h}\left(R_{t}^{o b s}(h)-R_{t}(h)\right)^{2} \\
\text { s.t. } c_{40}=-40(1,1,0)^{\prime}, d_{40}=0
\end{array}\right.
$$

where, for each date $t$ and maturity $h, R_{t}(h)$ is the theoretical yield determined by formula (6) in which the vector of parameters $\theta^{(o)}$ has been replaced by $\theta_{T}^{(n c)}\left(\lambda^{*}\right)$, and $R_{t}^{o b s}(h)$ indicates the observed one. Risk sensitivity parameter estimates of the Near-Cointegrated VAR(3) factor-based term structure model are presented in Table $3^{9}$. It is interesting to point out that our NCVAR(3) model has under the risk-neutral probability a degree of persistence larger than under the historical one, since its largest root is 0.994 in the first case and 0.987 in the second one. So, our framework implies a largest historical root much bigger the one based on the unconstrained VAR(3) model (0.93), but smaller than the risk-neutral one [compare with JPS(2010)].

\begin{tabular}{|c|c|c|c|c|c|c|c|c|c|c|}
\hline & $\gamma_{0}$ & $\gamma_{1}$ & & & $\gamma_{2}$ & & & $\gamma_{3}$ & & \\
\hline \multirow[t]{2}{*}{$r_{t}$} & -0.234 & 102.009 & 102.622 & -13.795 & 21.063 & 12.619 & -21.957 & -97.484 & -13.044 & 0.455 \\
\hline & {$[-4.912]$} & {$[6.615]$} & {$[5.374]$} & {$[-4.721]$} & {$[0.881]$} & {$[0.460]$} & {$[-7.432]$} & {$[-7.202]$} & {$[-0.823]$} & {$[0.187]$} \\
\hline \multirow[t]{2}{*}{$S_{t}$} & 0.022 & 49.605 & 92.903 & -1.080 & -98.565 & -81.329 & 7.816 & 34.913 & 35.646 & -3.002 \\
\hline & {$[0.331]$} & {$[1.812]$} & {$[2.707]$} & {$[-0.182]$} & {$[-2.227]$} & {$[-1.601]$} & [1.391] & {$[1.595]$} & {$[1.344]$} & {$[-0.687]$} \\
\hline \multirow[t]{2}{*}{$g_{t}$} & 1.615 & 72.856 & 156.141 & -44.240 & -253.550 & 94.835 & 8.570 & 82.669 & -422.016 & 55.639 \\
\hline & {$[1.460]$} & {$[0.165]$} & {$[0.284]$} & {$[-0.503]$} & {$[-0.361]$} & {$[0.119]$} & {$[0.099]$} & {$[0.240]$} & {$[-1.019]$} & {$[0.865]$} \\
\hline
\end{tabular}

Table 3: Risk sensitivity parameter estimates for the NCVAR(3) factor-based term structure model. $t$-values are in brackets.

\subsection{Cross-sectional reliability of the weighting parameter}

The purpose of this section is to provide, first of all, a further argument of the reliability of the value $\lambda^{*}=\lambda^{*}(40) \approx 0.26$, besides those mentioned at the end of Section 3 , and also to show the ability of our yield-to-maturity formula to explain the observed interest rates variability in terms of fitting performance.

\footnotetext{
${ }^{9}$ The risk sensitivity parameter estimates (obtained by CNLLS) of the CVAR(3), VAR(3) and VAR(1) factor-based term structure models are presented in Table a.xiii).
} 
The reliability check of the estimated averaging parameter is done in the following way: instead of using criterion (4) to fix $\lambda$, we fix it at the same time as the risk sensitivity parameters $\theta_{\gamma}=$ $\left(\gamma_{0}, \gamma_{1}, \gamma_{2}, \gamma_{3}\right)$, by minimizing the fitting error of the whole yield curve, that is by using the CNLLS methodology (8). This value is found to be $\lambda^{* *}=0.256$, very close to $\lambda^{*}(40) \approx 0.26$.

\begin{tabular}{l|rr|rrr}
\hline & $\begin{array}{r}\text { NCVAR(3) } \\
{\left[\lambda^{* *}=0.256\right]}\end{array}$ & $\begin{array}{r}\text { NCVAR(3) } \\
{\left[\lambda^{*}=0.262\right]}\end{array}$ & CVAR(3) & VAR(3) & VAR(1) \\
\hline Mean & 16.79 & 16.81 & 16.91 & 16.86 & 18.76 \\
Median & 12.11 & 12.22 & 12.89 & 12.55 & 16.02 \\
Std. Dev. & 13.80 & 13.88 & 14.02 & 13.96 & 15.23 \\
\hline
\end{tabular}

Table 4: Annualized Absolute Pricing Errors (Basis Points).

As far as the in-sample fit is concerned, we compare in Table 4 the annualized absolute yield-tomaturity errors of our selected $\operatorname{NCVAR}(3)$ factor-based term structure model with the performances of the competing $\operatorname{CVAR}(3), \operatorname{VAR}(3)$ and $\operatorname{VAR}(1)$ yield curve models. For each date $t$ and each estimated model, we compute, over the maturities used to estimate the risk sensitivity parameters $\theta_{\gamma}=\left(\gamma_{0}, \gamma_{1}, \gamma_{2}, \gamma_{3}\right)$, the pricing error in the following way:

$$
P E_{t}=\frac{\sum_{h}\left|R_{t}^{o b s}(h)-R_{t}(h)\right|}{H}
$$

where $R_{t}^{\text {obs }}(h)$ and $R_{t}(h)$ are, respectively, the (annualized) observed and model-implied yields, and where $H$ denotes the number of maturities used to estimate $\theta_{\gamma}$. Given the time series $P E_{t}$, we calculate for each model the associated mean and standard deviation. We see from table 4 that the fitting based on the NCVAR(3) estimates is slightly better than the one based on the CVAR(3) and $\operatorname{VAR}(3)$ estimates and much better than the one based on the VAR(1) model [see table a.xiv) for further details $]^{10}$.

\footnotetext{
${ }^{10}$ We have also verified, working with Campbell-Shiller regressions, the ability of our approach to explain the observed violation of the Expectation Hypothesis theory over the maturity spectrum, with $\operatorname{VAR}(1)$ and VAR(3) models failing for short maturities [see Jardet, Monfort and Pegoraro (2010), Table a.xv), for details]. We also have considered the case of a weighting parameter $\lambda$ optimally selected on the basis of a criterion of interest like the forecast of yields over several horizons, and found that our model is again able to provide a large reduction of the associated root mean squared forecast errors [see Jardet, Monfort and Pegoraro (2009c)].
} 


\section{The NCVAR-based Term Premia Measure}

The first subsection briefly introduces the concept of term premium, while the second one presents a comparison of the NCVAR(3)-based term premia measures with the ones extracted by the CVAR(3), VAR(3) and VAR(1) models, as well as the Kim and Wright (2005) one (for the 10-year horizon).

\subsection{Definition of the term premia}

Let us consider $R_{t}(h)$ and $r_{t}$, that is, the yield of maturity $h$ periods at time $t$, and the short rate. The former can be written as $R_{t}(h)=E X_{t}(h)+T P_{t}(h)$, where:

$$
E X_{t}(h)=-\frac{1}{h} \log E_{t}\left\{\exp \left[-\sum_{j=0}^{h-1} r_{t+j}\right]\right\}
$$

denotes the expectation part of $R_{t}(h)$, and

$$
T P_{t}(h)=R_{t}(h)-E X_{t}(h)
$$

is, by definition, the $h$-period term premium. Note that, since $R_{t}(h)=-\frac{1}{h} \log E_{t}^{\mathbb{Q}}\left\{\exp \left[-\sum_{j=0}^{h-1} r_{t+j}\right]\right\}$, $\mathbb{Q}$ denoting the risk-neutral probability measure, the term premium thus defined is unbiased in the sense that it is equal to zero if risk-neutral and historical dynamics are identical. Also note that $E X_{t}(h)$ is easily computed using the recursive equations (7), with $\gamma_{0}=0$ and $\gamma=0$ [see also Bernanke, Reinhart and Sack (2004)]. The spread of maturity $h$ periods at time $t, S_{t}(h)=R_{t}(h)-r_{t}$ can then be written as $S_{t}(h)=E X S_{t}(h)+T P_{t}(h)$, where $E X S_{t}(h)=E X_{t}(h)-r_{t}$ is the expectation part of the $h$-period spread.

\subsection{Comparison of term premia measures}

On the basis of the results presented in Section 3.2.2, our NCVAR(3) estimation provides (in terms of RMSFE, and among the competing models) the best measure of the 10-year term premium, that 
is, the best decomposition of the long-term spread into expectation part $E X S_{t}(40)$ and $T P_{t}(40)$. Let us consider a statistical comparison with the one extracted by the CVAR(3), VAR(3) and $\operatorname{VAR}(1)$ specifications (see table 5 and figure 6).

\begin{tabular}{l|cccc}
\hline & NCVAR(3) & CVAR(3) & VAR(3) & VAR(1) \\
\hline Mean & 1.35 & 1.43 & 1.25 & 1.19 \\
Std. Dev. & 1.08 & 1.09 & 1.62 & 1.47 \\
Corr. with $S_{t}$ & 0.77 & 0.92 & 0.32 & 0.20 \\
\hline
\end{tabular}

Table 5: Descriptive statistics of $T P_{t}(40)$ measures obtained from $\operatorname{NCVAR}(3), \operatorname{CVAR}(3), \operatorname{VAR}(3)$ and $\operatorname{VAR}(1)$ models. Corr. is the coefficient of correlation between $T P_{t}(40)$ and $S_{t}$.

As can be seen from table 5, our preferred measure of the term premium, based on the NCVAR(3) estimation, is the more stable one. It is less correlated with the spread than the CVAR(3)-based measure, but more than the $\operatorname{VAR}(3)$ and $\operatorname{VAR}(1)$ ones. In other words, our preferred NCVAR(3) estimation leads to a term premium that drives a great part of the spread variability, but not the quasi-totality, as it is the case for the $\operatorname{CVAR}(3)$ model in which $E X S_{t}(40)$ is close to zero ${ }^{11}$ (see figure 6). Looking at figure 6, we also see that the NCVAR(3)-based term premium measure moves between the measures obtained from the $\operatorname{VAR}(3)$ and $\operatorname{CVAR}(3)$ models. We also report, in figure 6, recessions (shaded bars) as dated by the National Bureau of Economic Research. We observe that the preferred (NCVAR-based) measure of term premium is, coherently with typical macro wisdom and in contrast with Rudebusch and Wu (2008) and Bauer (2010), clearly contra-cyclical. Figure 6 also highlights that the favored decomposition assigns the majority of the 10-year yield movements to the $E X_{t}(40)$ term, without overestimating its magnitude and variability as in the CVAR(3) case. In contrast, the OLS-based VAR decompositions of $R_{t}(40)$, based either on a $\operatorname{VAR}(3)$ or a $\operatorname{VAR}(1)$ model are strongly affected by the persistence problem and provide a completely different picture in which the long-term yield variability is driven by the term premium component [as in Kim and Orphanides (2007) and Beechey (2007)]. Observe also that our decomposition, coherently with the literature [see Backus and Wright (2007), Cochrane and Piazzesi (2008) and the references therein],

\footnotetext{
${ }^{11}$ When the short rate is considered as an $\mathrm{I}(1)$ (non stationary) process, the expectation part of the 10-year interest rate, $E X_{t}(40)$, is very close to the short rate and, thus, the expectation part of the spread, $E X S_{t}(40)$, is close to zero, making the 10-year spread almost equal to the term premium. This result highlights one of the limits of the CVAR approach for computing the term premium.
} 

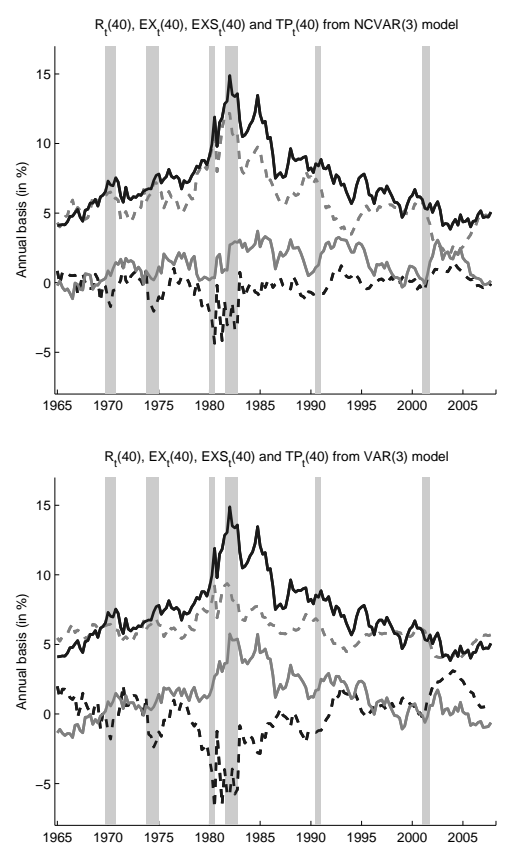
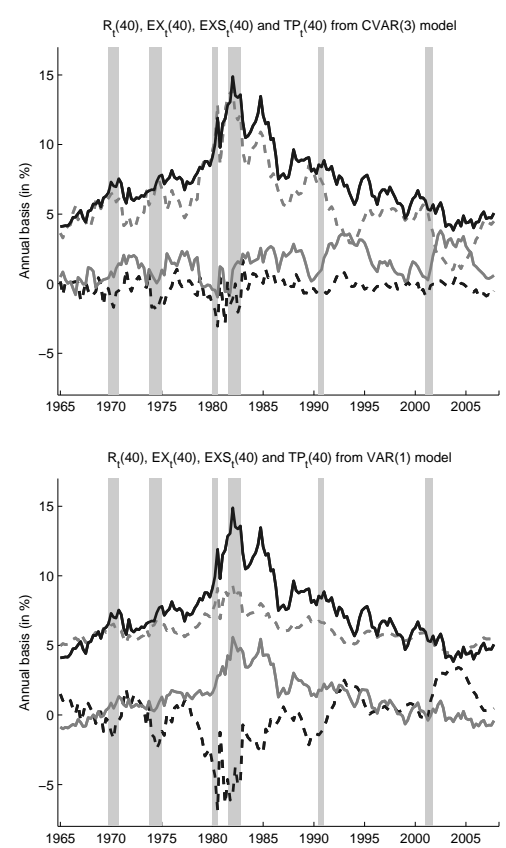

Figure 6:

Comparisons of model-based $E X_{t}(40)$ (grey dashed line), $T P_{t}(40)$ (grey solid line) and $E X S_{t}(40)$ (black dashed line) measures from NCVAR(3), CVAR(3), VAR(3) and VAR(1) models. The black solid line denotes $R_{t}(40)$, and shaded areas indicate recession periods (NBER).

explains the conundrum episode (from June 2004 to June 2006) by a sharp decrease of the term premium that exactly offsets the rise of expectation part. From figure 7 we can easily verify that these comments apply also to the decomposition of the 5-year interest rate and spread.

In figure 8 we consider a comparison with the $T P_{t}(40)$ measure taken by Rudebusch, Sack and Swanson (2007) as a representative one of the five they compare in their paper, namely the Kim and Wright (2005) measure (available only till 1990). This graph shows that, between the last two recessions in the sample, our $\operatorname{NCVAR}(3)$ measure displays similar features, including peaks and trough. Nevertheless, significant differences between these two measures are observed in the period 2001-2004 during which, the $\operatorname{NCVAR}(3)$ term premium is substantially higher than the Kim-Wright's one ${ }^{12}$. In particular, we note that the rise and the decrease of the term premium in

\footnotetext{
${ }^{12}$ During this period, the values of the NCVAR(3)-based measure of the term premium are closer to those obtained with the Rudebusch and $\mathrm{Wu}(2008)$ measure. Nevertheless, the latter seems to be neutral with respect to the business cycle [see Rudebusch, Sack and Swanson (2007) for further details].
} 

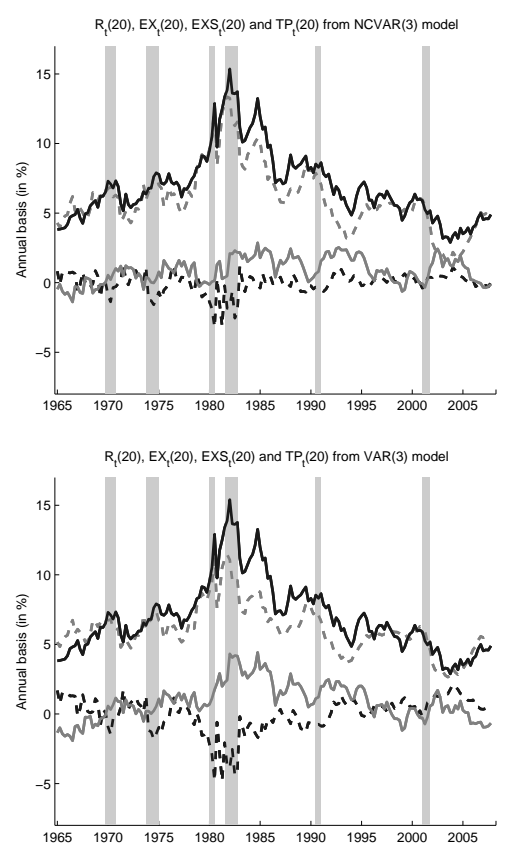
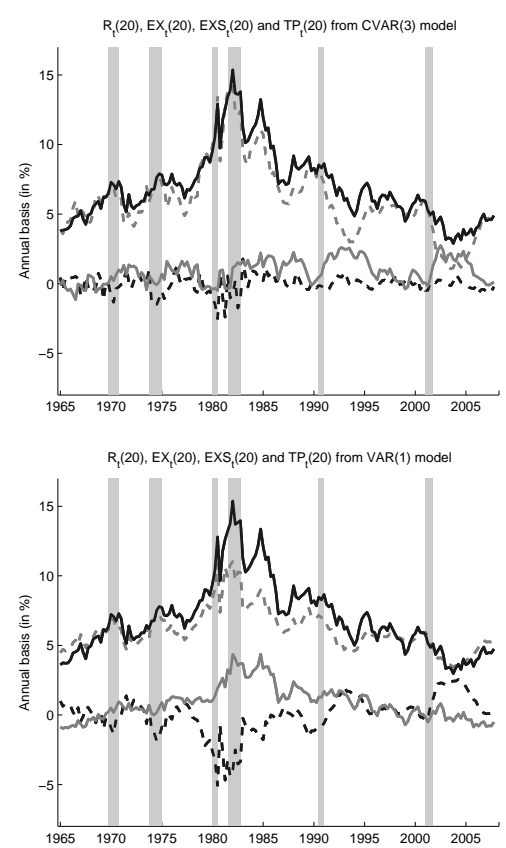

Figure 7:

Comparisons of model-based $E X_{t}(20)$ (grey dashed line), $T P_{t}(20)$ (grey solid line) and $E X S_{t}(20)$ (black dashed line) measures from NCVAR(3), CVAR(3), VAR(3) and VAR(1) models. The black solid line denotes $R_{t}(20)$, and shaded areas indicate recession periods (NBER).

the 2001 recession and in the 2004 conundrum episode, respectively, is more pronounced with the NCVAR(3) model. For comparison purposes we also present, in figure 8, the 10-year term premium obtained from the VAR(1) model à la Ang, Piazzesi and Wei (2006). In recent years, the VAR(1) measure tends to severely underestimate the risk level compared with our preferred measure.

\section{$6 \quad$ NIRF Analysis of the Term Premia}

\subsection{Motivating the New Information Response Function (NIRF) approach}

There exists an extensive literature emphasizing the predictive power of the spread of interest rates. However little is known about the specific contribution of each component of the spread, its expectation part and the term premium, in the explanation of this fact. This lack of agreement mainly concerns the specific effect of the term premium on future GDP. While practitioners view tends 


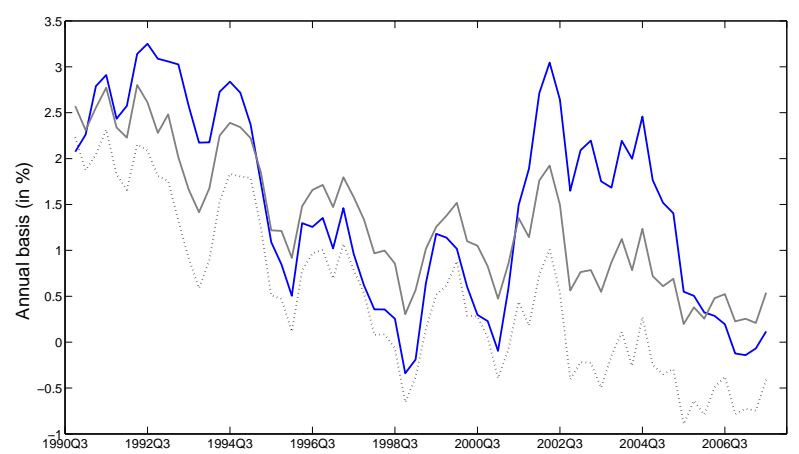

Figure 8:

Comparing NCVAR-based $T P_{t}(40)$ measure with Kim and Wright (2005).

NCVAR(3) model (blue solid line); Kim and Wright (2005) model (grey solid line); VAR(1) model (dotted line).

to suggest a negative relationship between both variables, empirical findings, most of them based on static regressions, seem to indicate either the opposite effect, or a non significant relationship. Hamilton and Kim (2002), and Favero, Kaminska and Södestrôm (2005), for instance, tend to conclude to a positive and significant relationship between the term premium and future activity. In contrast, Ang, Piazzesi and Wei (2006), Rudebusch, Sack and Swanson (2007), and Rosenberg and Maurer (2007) do not find significant link between the level of the term premium and future output growth.

In this section, we try to shed light on this debate by proposing a dynamic analysis of the relationship between the term premium and economic activity. More precisely, we are interested in measuring the differential impact of a shock on the term premium on the real GDP. For that purpose we follow the New Information Response Functions approach (NIRF thereafter) proposed by Jardet, Monfort and Pegoraro (2009b). This approach seems to be particularly well suited to our question of interest. First, it allows a direct analysis of the effects of a new information on any unobservable variable that is a filtered variable of our state process $X_{t}=\left(r_{t}, S_{t}, g_{t}\right)^{\prime}$, the term premium in our case. Second, constraints on this new information can be easily imposed. As we will show below, the latter point is particularly convenient to disentangle specific impact of a shock on the term premium from a shock on the expectation part of the spread. 
In what follows, we consider that the dynamics of the 3-dimensional state process $X_{t}=\left(r_{t}, S_{t}, g_{t}\right)^{\prime}$ is given by the Near-Cointegrated VAR(3) model described in the previous sections. Response functions obtained from our NCVAR(3) model are compared with those obtained from three competing models, VAR(3), CVAR(3) and the Ang-Piazzesi-Wei VAR(1) model. In doing so, we aim at analysing how our decomposition of the spread alter conclusions about the relationship between term premium and economic activity.

The first subsection summarizes the methodology, the second one focuses on the definition of the shocks, while the last one presents the responses to a shock on the spread, and to a shock on its expectation part and its term premium component.

\subsection{Definition of New Information Response Functions}

Let us consider a $n$-dimensional $\operatorname{VAR}(p)$ process $X_{t}$, possibly non-stationary. We denote by $\eta_{t}$ its innovation process. We want to measure the differential impact on $X_{t}, t=1, \ldots, T$, of a new information $I_{0}$ at date $t=0$ (by convention). Typically, this new information will be the value $h_{0}$ taken by some function $h\left(\eta_{0}\right)$ of the innovation of the process at $t=0$. More precisely, the NIRF is defined by:

$$
N I R F(t)=E\left(X_{t} \mid I_{0}, X_{\underline{-p}}\right)-E\left(X_{t} \mid X_{\underline{-p}}\right), t \geq 0
$$

where $X_{\underline{-p}}=\left(X_{-1}^{\prime}, \ldots, X_{-p}^{\prime}\right)^{\prime}$. Exploiting the linearity of the model we can show that $N \operatorname{IRF}(t)=$ $D_{t} \delta$ with $\delta=E\left(\eta_{0} \mid h\left(\eta_{0}\right)=h_{0}\right)$, and $D_{t}$ is the $t^{t h}$ Markov matrix coefficient of the MA representation of $X_{t}$ [see Jardet, Monfort and Pegoraro (2009b)].

This general concept of NIRF includes standard Impulse Response Functions like orthogonalized shocks, Uhlig (2005)'s impulse vectors, structural shocks or Pesaran and Shin (1998) "generalized" IRF. But the New Information Response Function is useful in a much more general context, in particular when considering shocks on filtered variables. More precisely, let us consider a $m$ dimensional process $\bar{X}_{t}$ obtained by applying a linear filter on $X_{t}$, namely $\bar{X}_{t}=F(L) X_{t}$ where $F(L)=\left[F_{1}(L), \ldots, F_{n}(L)\right]$ is a $(m \times n)$ matrix of polynomials in the lag operator. The innovation 
of $\bar{X}_{t}$ at $t=0$ is $\bar{\eta}_{0}=F(0) \eta_{0}$. Therefore, if the new information at $t=0$ is $\bar{h}\left(\bar{\eta}_{0}\right)=\bar{h}_{0}$, the $N I R F$ is $N I R F(t)=D_{t} \delta$ with $\delta=E\left(\eta_{0} \mid \bar{h}\left[F(0) \eta_{0}\right]=\bar{h}_{0}\right)$. Obviously, the new information may also be made of an information on both $\eta_{0}$ and $\bar{\eta}_{0}: h\left(\eta_{0}\right)=h_{0}$ and $\bar{h}\left(\bar{\eta}_{0}\right)=\bar{h}_{0}$, or $h\left(\eta_{0}\right)=h_{0}$ and $\bar{h}\left(F(0) \eta_{0}\right)=\bar{h}_{0}$. For our question of interest, $\bar{X}_{t}$ corresponds to the term premium or the expectation part of the spread.

\subsection{Definition of the shocks}

Given the affine structure of our model, the expectation part of the spread $E X S_{t}(40)$ and the term premium $T P_{t}(40)$ are obtained by applying a linear filter to $X_{t}=\left(r_{t}, S_{t}, g_{t}\right)^{\prime}$ :

$$
\begin{aligned}
E X S_{t}(40) & =F_{1,1}(L) r_{t}+F_{1,2}(L) S_{t}+F_{1,3}(L) g_{t} \\
T P_{t}(40) & =F_{2,1}(L) r_{t}+F_{2,2}(L) S_{t}+F_{2,3}(L) g_{t}
\end{aligned}
$$

Hence, the innovation at $t=0$ of $E X S_{t}(40)$ and $T P_{t}(40)$, denoted by $\bar{\eta}_{0,1}$ and $\bar{\eta}_{0,2}$ respectively are:

$$
\begin{aligned}
& \bar{\eta}_{0,1}=F_{1,1}(0) \eta_{0,1}+F_{1,2}(0) \eta_{0,2}+F_{1,3}(0) \eta_{0,3} \\
& \bar{\eta}_{0,2}=F_{2,1}(0) \eta_{0,1}+F_{2,2}(0) \eta_{0,2}+F_{2,3}(0) \eta_{0,3}
\end{aligned}
$$

where $\eta_{0,1}, \eta_{0,2}$ and $\eta_{0,3}$ are the innovations at $t=0$ of $r_{t}, S_{t}$ and $g_{t}$ respectively. In addition, by construction, we have $\eta_{0,2}=\bar{\eta}_{0,1}+\bar{\eta}_{0,2}{ }^{13}$.

In what follows, we first define the shock on the term premium as a shock on a spread that is completely generated by a move of the term premium. More precisely, we are interested in the dynamic effects of a 1 percentage point increase in the spread that would be completely due to a 1 percentage point increase in its term premium. In other words, the term premium shock is such that at date $t=0$ (date of the shock) the innovation of the expectation part of the spread is zero. Given our notation, this implies the following constraints $\bar{\eta}_{0,1}=0, \bar{\eta}_{0,2}=1$. In addition, we have to

\footnotetext{
${ }^{13}$ This implies that the $F_{i, j}(0)$ verify $F_{1,1}(0)+F_{2,1}(0)=0, F_{1,2}(0)+F_{2,2}(0)=1$ and $F_{1,3}(0)+F_{2,3}(0)=0$
} 
remember that interest rates are observed at the end of the period (end-of-quarter observations), and they contain an information covering a following period corresponding to the residual maturity, whereas $g_{t}$ is the growth rate of GDP between $t-1$ and $t$, and contains an information on the two previous quarters. Therefore, a shock on the spread, or on one of its components, occuring at date $t$ (end of the quarter), should have no effect on the growth rate of real GDP between $t-1$ and $t$. Accordingly, we impose an additionnal restriction to ensure that the growth rate of real GDP does not respond instantaneously to this kind of shocks. This implies the restriction $\eta_{0,3}=0$.

Finally, a shock on the term premium at date $t$ is fully characterized by the new information $I_{0}^{T P}=\left\{\bar{\eta}_{0,1}=0, \bar{\eta}_{0,2}=1, \eta_{0,3}=0\right\}$. Given our definition of the $N I R F$, we have to determine the value of the vector $\delta^{T P}=E\left(\eta_{0} \mid I_{0}\right)=E\left(\eta_{0} \mid \bar{\eta}_{0,1}=0, \bar{\eta}_{0,2}=1, \eta_{0,3}=0\right)$. Then, $\delta^{T P}=\left(\delta_{1}^{T P}, 1,0\right)^{\prime}$ with, from equation (15), $\delta_{1}^{T P}=E\left(\eta_{0,1} \mid I_{0}^{T P}\right)=\frac{1-F_{2,2}(0)}{F_{2,1}(0)}$.

Conversely, a shock on the expectation part of the spread is defined as a shock on the spread that is entirely due to a move of its expectation part at the date of the shock $(t=0)$. More precisely, we focus on dynamic effects of a 1 percentage point increase in the spread that would be completely generated by a 1 percentage point increase in its expectation component. Given our notations, the new information now includes $\bar{\eta}_{0,1}=1$ and $\bar{\eta}_{0,2}=0$. For reasons mentioned above, we also assume that this increase has no instantaneous effect on the real GDP, that is $\eta_{0,3}=0$. Finally, the shock on the expectation part of the spread is fully characterized by the new information $I_{0}^{E X S}=\left\{\bar{\eta}_{0,1}=1, \bar{\eta}_{0,2}=0, \eta_{0,3}=0\right\}$. From equation (14) we immediately obtain $\delta^{E X S}=\left(\delta_{1}^{E X S}, 1,0\right)^{\prime}$ where $\delta_{1}^{E X S}=E\left(\eta_{0,1} \mid I_{0}^{E X S}\right)=\frac{1-F_{1,2}(0)}{F_{1,1}(0)}$. For sake of comparison, we also report the response of GDP to a shock on the spread, say a 1 percentage increase in the spread, without disentangling which of its component is behind this shift. In this case, the new information is $I_{0}^{S}=\left\{\eta_{0,2}=1, \eta_{0,3}=0\right\}$. Hence, $\delta^{S}=E\left(\eta_{0} \mid \eta_{0,2}=1, \eta_{0,3}=0\right)=\left(\delta_{1}^{S}, 1,0\right)^{\prime}$, where $\delta_{1}^{S}=E\left(\eta_{0,1} \mid \eta_{0,2}=1, \eta_{0,3}=0\right)$. In the gaussian case, $\delta_{1}^{S}$ is the coefficient of $\eta_{0,2}$ in the theoretical regression of $\eta_{0,1}$ on $\eta_{0,2}$ and $\eta_{0,3}$.

Note that, since $\delta^{T P}=\left(\delta_{1}^{T P}, 1,0\right), \delta^{E X S}=\left(\delta_{1}^{E X S}, 1,0\right)$ and $\delta^{S}=\left(\delta_{1}^{S}, 1,0\right)$, it is always possible 
to find a scalar $\mu$ such that $\delta^{S}=\mu \delta^{E X S}+(1-\mu) \delta^{T P}$. Therefore, responses to a shock on the spread are linear combinations of responses to a shock on its expectation part and the term premium with weights summing to one ${ }^{14}$.

\subsection{Responses of the GDP to a shock on the spread or its components}

Figures 9, 10 and 11 report responses of the real GDP to a 1 percentage point shock in the 10-year spread, the expectation part of the spread and the term premium, as defined previously ${ }^{15}$.

Regarding the shock on the spread (figure 9) we observe that an increase in the spread of 1 percentage point (that is 4 percentage point in annual basis) leads, after 20 quarters, to an increase in real GDP that ranges between $4 \%$ (that is an annual average growth rate equal to $0,8 \%$ ) and $3 \%$ (average annual growth rate of $0,6 \%$ ) depending on the model. This result confirms the well documented empirical finding of a positive relationship between the slope of the yield curve and future activity. In addition responses of real GDP obtained with CVAR(3), VAR(3) and NCVAR(3) models are very similar. Responses obtained from a VAR(1) models are smaller, but display the same tendency.

We obtain the same kind of conclusions with a shock on the expectation part of the spread (figure 10): responses obtained with the four models are not very different. With all the models, a 1 percentage point increase in the spread that is entirely caused by a 1 percentage point increase in its expectation part leads to an increase in future real activity (with a range between $3 \%$ and $4 \%$ after 20 quarters). This confirms the conventional interpretation of the predictive power of the spread which suggests that this shock could be interpreted as a monetary policy shock. According to this view, the increase in the expectation part of the spread is caused by an expansionary monetary

\footnotetext{
${ }^{14}$ Let denote by $N I R F^{S}(t), N I R F^{T P}(t)$ and $N I R F^{E X S}(t)$ the New Information Response Functions at date $t$ to shock on the spread, the term premium and the expectation part of the spread respectively. By definition of the $N I R F$, we have $N I R F^{S}(t)=D_{t} \delta^{S}, N I R F^{T P}(t)=D_{t} \delta^{T P}, N I R F^{E X S}(t)=D_{t} \delta^{E X S}$. With $\delta^{S}=\mu \delta^{E X S}+(1-$ $\mu) \delta^{T P}$, we immediately obtain: $N \operatorname{IRF}^{S}(t)=\mu N \operatorname{IRF}^{T P}(t)+(1-\mu) N \operatorname{IRF} F^{E X S}(t)$.

${ }^{15}$ See Jardet, Monfort and Pegoraro (2009c) for the responses of yields of various maturities and responses of their corresponding term premia and expectation components to these shocks. In addition, in Jardet, Monfort and Pegoraro (2010), we also report responses of the real GDP to a 1 percentage shock in the $h$-year spread and its component, for $h=\{1 y, 5 y\}$.
} 


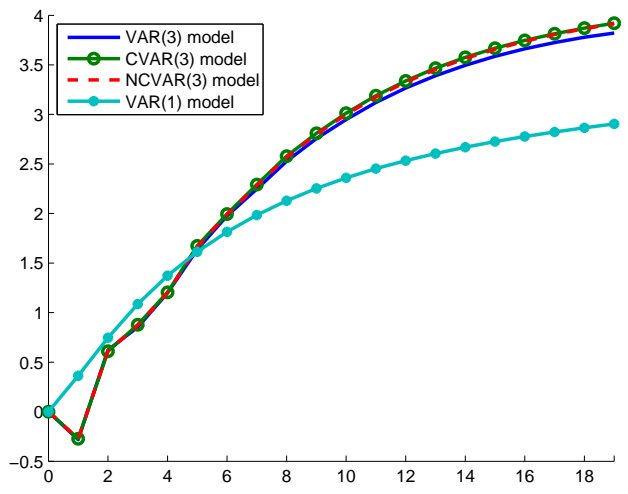

Figure 9: Response of GDP to a shock on the 10-year spread

policy, that is a decrease in the short term interest rate $^{16}$ that improves the economic financing condition and finally boosts economic activity.

Finally, figure 11 shows responses of real GDP to a 1 percentage point increase in the spread that is entirely due to a 1 percentage point increase in its term premium (the term premium shock). Contrary to previous cases, shock on the term premium generates responses of real GDP that are very different depending on the model considered. More precisely, responses of real GDP obtained after a shock on the VAR(1) model are close to zero. This result confirms empirical results of Ang, Piazzesi and Wei (2006) which are based on a VAR(1) framework and on static regressions, and conclude to a no significant relationship between the term premium and future activity. Conversely, responses obtained from $\operatorname{VAR}(3), \operatorname{CVAR}(3)$ and $\operatorname{NCVAR}(3)$ models indicate a negative relationship for short horizon (smaller than one year), whereas it is positive for longer horizon (after 20 quarters the increase in the real GDP ranges between $3 \%$ and 4,5\%). A similar result has been recently shown in Joslin, Priebsch and Singleton (2010) by means of their Markovian of order one term structure model characterized by spanned and unspanned macro risks. They show that a shock in the "in-nine-for-one" forward term premium mainly affects industrial production growth by means

\footnotetext{
${ }^{16}$ See Jardet, Monfort and Pegoraro (2009c) for details regarding responses of the short rate and rates of various maturities to these shocks. More precisely, we observe that a shock on the expectation part of the spread leads to a decrease in the short term interest rate. In addition, we show that responses of various variables obtained after a shock on the short term interest rate, which could be interpreted as a monetary policy shock, are close to the ones obtained with a shock on the expectation part of the spread.
} 
of its unspanned component, while the spanned one is found to be unaffected. Our NCVAR(3) yield curve model, like the $\operatorname{VAR}(3)$ and CVAR(3) models, in which macro risk is spanned by present and past values of the term structure, provides an alternative route to explain the effect of term premia shocks on future economic activity.

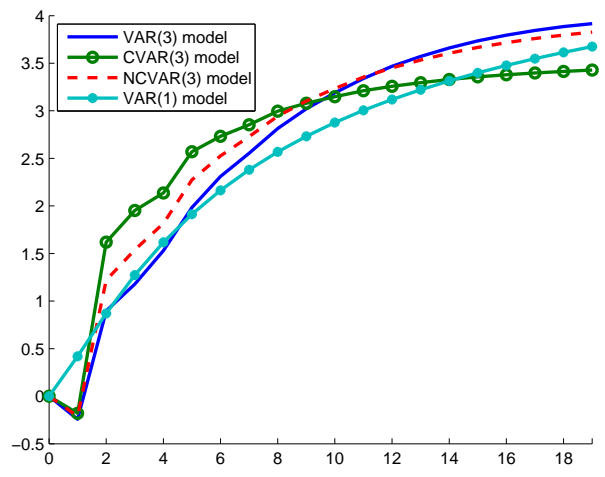

Figure 10:

Impulse response of GDP to a shock on the expectation component of the 10-year spread.

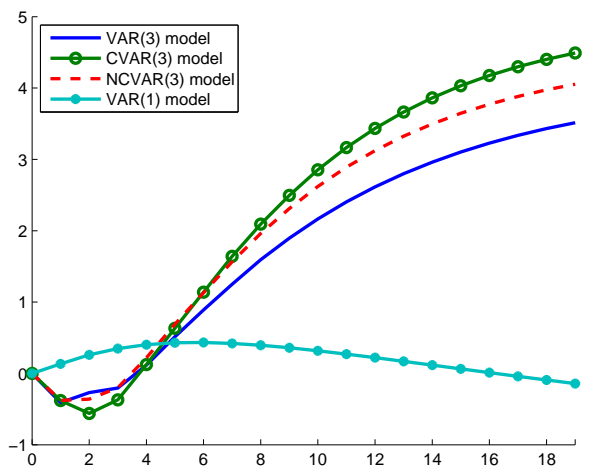

Figure 11:

Impulse response of GDP to a shock on the 10-year term premium.

To give an economic explanation to the response of the term premium shock is not straightforward because we need more ingredients to be able to interpret accurately the shock, such as for instance inflation, private investment or government spending. Notwithstanding, the shape of the response, a decrease followed by an increase in the GDP, provide us some insight about the nature of the shock. For instance, we can conjecture that the term premium shock could be compared with a shock on government spending that would be financed by an issue of long term bonds [see also Greenwood and Vayanos (2008)]. Such a policy can generate two opposite effects on activity. First, higher long term interest rates tends to reduce private investment, and have negative effect on real GDP. Second, public investment tends to boost activity. Our results suggest that the first effect dominates in the short run, explaining the decreasing trend of real GDP during the first year, and is progressively offset by the second effect, leading the real GDP to increase in the long run. Of course, at this stage of our analysis we can only venture some interpretation that one has to verify with a more accurate macroeconomic (structural) model [see, for instance, Rudebusch and 
Swanson (2008)]. In addition, we can think that the ambiguity found in empirical results based on static regressions of the term premium component on future activity, could stem from the changing sign of this relationship over the period that follows the shock.

Finally, based on our "preferred" NCVAR(3) estimation, our results seem to speak in favor of a positive long run relationship between the term premium and future activity. In addition, this analysis highlights that the model used in measuring the term premium is a key element when one wants to gauge whether or not shifts in the term premium affect future activity. Notably, the number of lags seems to be critical. This point appears to be less important when one focuses on the effects of a shock on the spread or on its expectation part.

\section{Conclusions and Further Developments}

In this paper we have proposed potential solutions to the computation of the term premia and to their ambiguous relationship with future economic activity. This problem has been handled, first, by using an averaging estimator [à la B. Hansen (2010)] to draw reliable forecasts from a (Near-Cointegrated) VAR(3) model in order to extract reliable term premia measures. The term premia thus obtained provide a decomposition of the long yields which are quite different from those obtained by the $\operatorname{VAR}(3), \operatorname{CVAR}(3)$ or $\operatorname{VAR}(1)$ models, especially in the recent years. Then, the general concept of New Information Response Function (NIRF), introduced by Jardet, Monfort and Pegoraro (2009b), has been used to study the effects on future GDP growth induced by a shock on term premia. The two new features of our econometric approach, namely the averaging estimation and the number of lags, play an important role in the empirical findings, the first feature being central for the computation of the term premia and the second one for the evaluation of the responses to shocks.

From a macroeconomic point of view, the starting point of our analysis has been a 3-dimensional VAR model with GDP growth [as in APW (2006)] that guarantees at the same time a parsimonious parametrization of the model and ease of estimation. It is clear that it would be useful to extend the 
state vector in order to introduce other relevant information like the inflation rate [see Bikbov and Chernov (2010)]. This variable is another well known nearly non-stationary process that provides an additional source of persistence that one has to handle (in addition to the interest rate persistence) in order to provide reliable measures of inflation and real rate expectations (and associated real rate and inflation risk premia). The objective of an ongoing research work is to extract these measures by means of the Near-Cointegrated modelling and to consider a comparison with other approaches where yield and inflation persistence is taken into account by means of additional data sources like survey forecasts on interest rates and inflation rates [see Kim and Orphanides (2005) and Chernov and Mueller (2008)].

From an econometric point of view, it is also known that the persistence problem (and associated forecast performances) can be tackled in a way different from the above mentioned averaging estimator. For instance, it would be possible to try to extend to macro-finance models the switching regime approach which has been used successfully in pure finance models [see Bansal and Zhou (2002), Bansal, Tauchen and Zhou (2004), Dai, Singleton and Yang (2007) and Monfort and Pegoraro (2007)] and thus checking how persistence properties are transformed within each regime and verify if prediction performances improve [see Veronesi and Yared (2000), Evans (2003), Ang, Bekaert and Wei (2008) and Bikbov and Chernov (2008)]. Another possibility could be the shifting endpoint methodology of Kozicki and Tinsley (2001a, 2001b). A comparison between these methodologies and the Near-Cointegrated one will be considered in future research. 


\section{R E F E R E N C E S}

Ang, A., Bekaert, G., (2002): "Short Rate Nonlinearities and Regime Switches", Journal of Economic Dynamics and Control, 26, 1243-1274.

Ang, A., Bekaert, G., Wei, M. (2008): "Term Structure of Real Rates and Expected Inflation", The Journal of Finance, 63(2), 797-849.

Ang, A., Piazzesi, M., Wei, M., (2006): "What does the Yield Curve tell us about GDP Growth", Journal of Econometrics, 131, 359-403.

Backus, D., and Wright, J., (2007): "Cracking the Conundrum", Board of Governors of the Federal Reserve System, Working Paper 2007-46.

Bansal, R., Zhou, H., (2002): "Term Structure of Interest Rates with Regime Shifts", Journal of Finance, 57, 1997-2043.

Bansal, R., Tauchen, G., Zhou, H., (2004): "Regime Shifts, Risk Premiums in the Term Structure, and the Business Cycle", Journal of Business and Economic Statistics, 22(4), 396-409.

Bauer, M., (2010): "Term Premia and the News", Federal Reserve Bank of San Francisco, Working Paper.

Bernanke, B.S., Reinhart, V.R., and Sack, B. (2004): "Monetary Policy Alternatives at the Zero Bound: An Empirical Assessment", Board of Governors of the Federal Reserve System, Working Paper 2004-48.

Beechey, M., (2007): "A Closer Look at the Sensitivity Puzzle: The Sensitivity of Expected Future Short Rates and Term Premia to Macroeconomic News", Board of Governors of the Federal Reserve System, Working Paper 2007-06.

Bikbov, R., and Chernov, M., (2008): "Monetary Policy Regimes and the Term Structure of Interest Rates", London Business School, Working Paper.

Bikbov, R., and Chernov, M., (2010): "No-Arbitrage Macroeconomic Determinants of the Yield Curve", London Business School, Journal of Econometrics, forthcoming. 
Cochrane, J., and Piazzesi, M., (2008): "Decomposing the Yield Curve", Graduate School of Business, University of Chicago, Working Paper.

Chernov, M., Mueller, P., (2008): "The Term Structure of Inflation Expectations", London Business School, Working Paper.

Dai, Q., Singleton, K., Yang, W., (2007) : "Regime Shifts in a Dynamic Term Structure Model of U.S. Treasury Bond Yields", Review of Financial Studies, 20(5), 1669-1706.

Duffee, G., Stanton, R., (2008): "Evidence on Simulation Inference for Near Unit-Root Processes with Implications for the Term Structure", Journal of Financial Econometrics, 6, 108-142.

Evans, M., (2003): "Real Risk, Inflation Risk, and the Term Structure", The Economic Journal, $113,345-389$.

Favero, C., Kaminska, I., Södeström, U., (2005): "The Predictive Power of the Yield Spread: Further Evidence and a Structural Interpretation", Working Paper, Università Bocconi.

Garcia, R., Luger, R., (2007): "Risk Aversion, Intertemporal Substitution, and the Term Structure of Interest Rates", Working Paper, Université de Montreal.

Gourieroux, C., Monfort, A. (1996): "Simulation based econometric methods", Oxford University Press.

Gourieroux, C., Monfort, A., Renault, E., (1993): "Indirect Inference", Journal of Applied Econometrics, 8, S85-S118.

Gourieroux, C., Renault, E., Touzi, N. (2000): "Calibration by simulation for small sample's bias correction", in Simulation-Based Inference in Econometrics, Mariano, Schuermann, Weeks eds, Cambridge University Press.

Gray, S., (1996): "Modeling the Conditional Distribution of Interest Rates as a Regime Switching Process", Journal of Financial Economics, 42, 27-62.

Greenwood, R., and Vayanos, D., (2008): "Bond Supply and Excess Bond Returns", Harvard Business School, working paper.

Gürkaynak, R., Sack, B., Wright, J., (2007), The U.S. Treasury Yield Curve: 1961 to the Present", 
Journal of Monetary Economics, 54, 2291-2304.

Hamilton, J.D., Kim, D.H., (2002): "A re-examination of the predictability of the yield spread for real economic activity", Journal of Money, Credit, and Banking, 34, 340-360.

Hansen, B., (2010): "Averaging Estimators for Autoregressions with a Near Unit Root", Journal of Econometrics, 158, 142-155.

Hansen, L.P., and Sargent, T.J., (2007): "Robustness", Princeton University Press.

Hansen, L.P., and Sargent, T.J., (2008): "Fragile Beliefs and the Price of Model Uncertainty", University of Chicago, working paper.

Jardet, C., Monfort, A., and Pegoraro, F., (2009a): "Persistence, Bias, Prediction and Averaging Estimators", Banque de France Working Paper.

Jardet, C., Monfort, A., and Pegoraro, F., (2009b): "New Information Response Functions", Banque de France Working Paper.

Jardet, C., Monfort, A., and Pegoraro, F., (2009c): "No-Arbitrage Near-Cointegrated VAR $(p)$ Term Structure Models, Term Premia and GDP Growth", Banque de France Working Paper.

Jardet, C., Monfort, A., and Pegoraro, F., (2010): "Online Appendix for 'No-arbitrage NearCointegrated $\operatorname{VAR}(p)$ Term Structure Models, Term Premia and GDP Growth' ", available at the website http://www.crest.fr/pageperso/pegoraro/pegoraro.htm.

Joslin, S., Priebsch, M., and Singleton, K., (2010): "Risk Premiums in Dynamic Term Structure Models with Unspanned Macro Risks", Graduate School of Business, Stanford University, Working Paper.

Kendall, M.G. (1954): "A note on bias in the estimation of autocorrelation", Biometrika, 41, 403404.

Kim, D.H., and Orphanides, A., (2005): "Term Structure Estimation with Survey Data on Interest Rate Forecasts", Board of Governors of the Federal Reserve System, Working Paper 2005-48.

Kim, D.H., and Orphanides, A., (2007): "The Bond Market Term Premium: what is it, and how can we measure it?", Bank of International Settlement, Quarterly Review. 
Kim, D.H., and Wright, J., (2005): "An Arbitrage-Free Three-Factor Term Structure Model and the Recent Behavior of Long-Term Yields and Distant-Horizon Forward Rates", Board of Governors of the Federal Reserve System, Working Paper 2005-33.

Kozicki, S., and Tinsley, P.A., (2001a): "Term Structure Views of Monetary Policy Under Alternative Models of Agent Expectations", Journal of Economic Dynamics and Control, 25, 149-184.

Kozicki, S., and Tinsley, P.A., (2001b): "Shifting Endpoints in the Term Structure of Interest Rates", Journal of Monetary Economics, 47, 613-652.

Monfort, A., Pegoraro, F., (2007): "Switching VARMA Term Structure Models", Journal of Financial Econometrics, 5(1), 105-153.

Pesaran, M.H., Shin, Y., (1998): "Generalized Impulse Response Analysis in Linear Multivariate Models", Economic Letters, 58(1), 17-29.

Rosenberg, J.V., Maurer, S., (2007): "Signal or Noise? Implications of the Term Premium for Recession Forecasting", Federal Reserve Bank of New York Economic Policy Review, forthcoming. Rudebusch, G.D., Sack, B., Swanson, E., (2007): "Macroeconomic Implications of Changes in the Term Premium", Federal Reserve Bank of St. Louis Review, 89(4), 241-269.

Rudebusch, G.D., Swanson, E., (2008): "The Bond Premium in a DSGE Model with Long-Run Real and Nominal Risks", Federal Reserve Bank of San Francisco, working paper.

Rudebusch, G.D., Wu, T. (2008): "A Macro-Finance Model of the Term Structure, Monetary Policy, and the Economy", Economic Journal, 118, 906-926.

Svensson, L.E.O., (1994): "Estimating and Interpreting Forward Rates: Sweden 1992-4", National Bureau of Economic Research Working Paper n. 4871.

Uhlig, H., (1994): "What Macroeconomists Should Know about Unit Roots: A Bayesian Perspective", Econometric Theory, 10(3/4), 645-671.

Veronesi, P., and Yared, F., (2000): "Short and Long Horizon Term and Inflation Risk Premia in the US Term Structure", Working Paper, University of Chicago - GSB. 